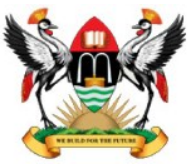

East African School of Higher Education Studies \& Developmen

\title{
Effects of Managerial Skills required in Entrepreneurship among Undergraduates in Oyo State, Nigeria
}

\author{
Banjo James O. S. ${ }^{1}$, Falola Oluwatoyin A. ${ }^{1, *}$, Ganiyu Y. Kabiru ${ }^{1}$ \\ ${ }^{1}$ Department of Agricultural Science, Tai Solarin University of Education [ ${ }^{*}$ Corresponding \\ author: okewoyeoa@tasued.edu.ng]
}

\begin{abstract}
Nigeria must pay attention to the growth of entrepreneurship in order to move out of the disturbingly high level of unemployment and poverty. Therefore, entrepreneurship education is one of the most promising strategies for rescuing the country from the burden of poverty and youth unemployment. Taking cognizance of this fact, this study examined the effects of the managerial skills among university undergraduates of Agriculture in Oyo State, Nigeria. Following a survey research design, data was collected from a sample of 120 respondents. The data were analysed using descriptive statistics. The findings were that there is no significant difference in the mean responses of males and females on the managerial skills required for entrepreneurship. It is recommended that government changes the way it perceives entrepreneurial activities; reduces the administrative burden on entrepreneurs; and provides adequate funds to Universities to enable them to establish and equip entrepreneurial development centres.
\end{abstract}

Keywords: BTVET; Agriculture; Curriculum innovation.

\section{$1 \quad$ Introduction}

Management theory and strategy research urge us to consider the entrepreneurial and creative dimensions of management even in situations where small and medium entrepreneurs are confronted with fierce and dynamic competition, complex and turbulent business environments, demanding and powerful customers, and limited resources. It is not easy for small and medium entrepreneurs to find or develop a promising strategic path of organizational development when the ordinary business seems to attract almost all the available forces of the firm. Nevertheless, innovative potential and flexibility due to low formal complexity of the organization, closeness to the customer, 
independence from outside control and the deep impact of the owner on the business are typical attributes of small business firms.

There has been a great deal of attention paid to the subject of entrepreneurship as a means of sustaining the economies of nations. This has stemmed primarily from the findings of economic analysts that small firms contribute considerably to economic growth and development. Moreover, many men and women have chosen entrepreneurial careers because doing so seems to offer them greater economic and psychological rewards than does the large company route (Zahra \& George, 2002).

Entrepreneurship education helps to develop a pool of potential entrepreneurs who are well equipped with skills to manage small and medium scale industries (Amesi, 2011). It involves the acquisition of skills, ideas and managerial abilities necessary for self-reliance. Agbaeze (2007) recognized entrepreneurship as that which is associated with different kinds of activities relating to the establishment and operation of a business enterprise. These activities may include identification to exploit for profit, promotion and establishment of a business enterprise. Others are distribution of goods and services; organization and management of the human and material resources for the attainment of the objectives of the enterprise; risk bearing; and innovation. Besides, entrepreneurship education has also been viewed as a learning process that imbibes in the learners traits and competencies such as team spirit, leadership, problem-solving, negotiation skills, self-direction and selfmanagement, unlike the traditional stereotype education, which places less attention on skills and practical needs of the world of work (Soskice, 2013).

Those with a managerial outlook are often in a great position to succeed as entrepreneurs, except for two big misconceptions that lead to massive problems. Many managers believe that if a business is not working, the solution lies in hiring more employees. They throw extra bodies at the problem, but this may only aggravate the situation because it could fail to address the underlying root cause of the difficulty or lack of profitability. Another mistaken belief that is common to this mind-set is that the route to success is through growth, not profit growth but overall structural growth of the enterprise itself. Once again, bigger is not necessarily better unless and until the fundamentals are sound and efficient. Growing larger to fix the problems of a small business only generates a much bigger company with problems that are expanded, magnified, and much more expensive to remedy. The most misstep common to the managerial attitude is that the entrepreneur wants to be the boss, even if that means sacrificing the talent or potential of employees. To give orders and be in charge requires no great skill or aptitude, but to be a leader, one who knows how to inspire and train others to rise to greater heights, is a rare quality. Managers who become leaders succeed because they accept the challenge and responsibility of ensuring that others under their wings also succeed and 
flourish. By getting the most out of employees, managers themselves are able to delegate aspects of their businesses to others and set higher goals. Those who say they cannot find good employees usually mean they lack what it takes to attract or create good employees and as a consequence they also lack what it takes to succeed as an entrepreneur. But those who not only manage but also lead can rise to the next level and become owners/leaders, one step closer to the real definition of an entrepreneur.

It is with cognizance of the foregoing that this study undertook to assess the relative effects of managerial skills that exist between University undergraduates' lecturers and entrepreneurs in the field of Agriculture in Oyo State, Nigeria. The study attempted to respond to one major research question: what are the managerial skills required by the University Undergraduates of Agriculture? And it was hypothesised that "there is no significant difference in the mean response of male and female respondents on the needed managerial skills among University undergraduates of Agriculture".

\section{Methodology}

The study employed a descriptive and analytic survey research design. This was done to establish how University undergraduates of Agriculture connect and sort information from numerous sources and use it to make decisions and to arrange and distribute work among members of their work group with the view to accomplish the organization's goals. Simple random sampling was used to select a sample of 120 respondents who included university lecturers and entrepreneurs in the Faculty of Agriculture. Data was collected using a selfadministered semi-structured questionnaire. The data collected were analysed using descriptive statistics. The hypothesis was tested at the level of confidence alpha $=.05$ using a Student-t test.

\section{Findings and Discussion}

The findings on the respondents' view of the managerial skills undergraduates require are summarized in Table 1. 
Table 1: Distribution of respondents by managerial skills required by undergraduates $(\%, N=120)$

\begin{tabular}{llllllll}
\hline Managerial Skills & VHR & HR & R & NR & & Mean & SD \\
\hline Ability to compel and encourage employees & 49 & 32 & 18 & 1 & 100 & 3.29 & 0.793 \\
Ability to clarify and solve problems for others & 43 & 38 & 17 & 2 & 100 & 3.23 & 0.786 \\
Ability to coordinate effectively & 43 & 39 & 18 & & 100 & 3.26 & 0.739 \\
Ability to use natural skills & 43 & 33 & 24 & & 100 & 3.18 & 0.799 \\
Ability to perform and manage daily activities of & 47 & 33 & 20 & & 100 & 3.27 & 0.775 \\
the business & & & & & & & \\
Ability to enforce written rules and procedures & 48 & 30 & 23 & & 100 & 3.25 & 0.802 \\
Ability to manage multiple business & 46 & 33 & 20 & 1 & 100 & 3.23 & 0.807 \\
Ability to take strong decisions & 46 & 33 & 20 & 1 & 100 & 3.23 & 0.807 \\
Ability to delegate positions of authority & 37 & 43 & 20 & & 100 & 3.17 & 0.737 \\
Ability to get people to perform operations & 37 & 38 & 25 & 1 & 100 & 3.10 & 0.803 \\
willingly & & & & & & & \\
Ability to maintain resources for optimum & 45 & 34 & 20 & 1 & 100 & 3.22 & 0.825 \\
production & & & & & & & \\
Weighted mean $=3.22$ & & & & & & \\
\hline
\end{tabular}

KEY: Very highly required (VHR); Highly required (HR); Required (R); Not required (NR) Standard Deviation (SD)

Table 1 shows the respondents response to managerial skills required by the University Undergraduates of Agriculture. The result revealed a weighted mean score of 3.22 out of the maximum 4.00 , which is higher than the standard average mean of 2.50 . This implies that respondents agreed that University undergraduates of agriculture need to have high level of managerial skills. The results of the hypothesis test are shown in Table 2.

Table 2: Mean difference in perception of managerial skills of undergraduates require

\begin{tabular}{lllllll}
\hline Variables & $\mathrm{N}$ & Mean & Std. Dev. & $\mathrm{Df}$ & $\mathrm{t}$ & P-value \\
\hline Male & 69 & 35.17 & 7.13 & 118 & -0.476 & $0.635^{*}$ \\
Female & 51 & 35.8 & 7.22 & & & \\
\hline
\end{tabular}

* Not significant at $\mathrm{P}<.05$

Table 2 shows that there was no significant difference in the mean response of male and female respondents on the needed managerial skills of University undergraduates of Agriculture $(\mathrm{P}>.05)$. Hence, the null hypothesis was rejected.

These findings indicated that University undergraduates of Agriculture need to have high level of managerial skills. The result may be due to the fact the University undergraduates of Agriculture do not have the skills for planning, organizing, coordinating, controlling, budgeting and staffing. This result contradicts the work of Schneider (2007) who argues that there is a function 
which is necessary to set up a farm, the function of entrepreneurs to take other persons' risks of income. Taking and managing risks is a function that has to be executed not only in times of the start-up of a farm but later on, during the running of the farm enterprise established, as well.

Based on the findings of the study and data analysis relating to relative effects of managerial skills required and its significance in entrepreneurship education among University undergraduates of Agriculture in Oyo State. It was concluded that University undergraduates of agriculture need to have high level of managerial skills. Therefore, the following recommendations are made:

1. Government at all level needs to have a positive perception of entrepreneurial activities; reduce the administrative burden on entrepreneurs, and coordinate among their agencies to ensure that the necessary resources are directed to where they are mostly needed. In doing so, friendly legislation that can support small and medium entrepreneurial should be formulated and implemented.

2 The intending entrepreneurs should endeavour to inculcate the habit of planning, organizing, coordinating, directing, staffing, controlling and budgeting in relating to managerial skills in entrepreneurship education.

\section{References}

Agbaeze, E. K. (2007). Development of entrepreneurship: the Nigerian perspective, Enugu: Precision Publishers Ltd.

Amesi, J. (2011). Critical characteristics and qualities needed for successful entrepreneurship as perceived by successful female entrepreneurs in the Niger Delta: Unpublished PhD Dissertation, Nnamdi Azikiwe University Awka, Anambra State.

Schneider, Dieter (2007). Betriebswirtschaftslehre, Vol. 3: Theorie der Unternehmung, Oldenbourg: Munich/Vienna.

Soskice, D. (2013). Social Skills from Mass Higher Education: Rethinking the company-based initial training paradigm. Oxford review of Economic Policy. 9(3).

Zahra, S. A. \& George, G. (2002). International entrepreneurship: The current status of the field and future research agenda. In M. A. Hitt; R. D. Ireland; S. M. Camp, \& D. L., Sexton (eds.) Strategic Entrepreneurship: Creating a New Mindset, Oxford: Blackwell Publishers. 